\title{
Cardiovascular Drug Discovery: A Perspective from a Research-Based Pharmaceutical Company
}

\author{
G. Gromo', J. Mann², and J.D. Fitzgerald ${ }^{3}$ \\ ${ }^{1}$ F. Hoffmann-La Roche AG, CH-4070 Basel, Switzerland \\ ${ }^{2}$ Translational Medicine, Cardiovascular and Metabolism, F. Hoffmann-La Roche AG, CH-4070 Basel, \\ Switzerland \\ ${ }^{3}$ Materiamedica, Knutsford WA16 6JR, United Kingdom \\ Correspondence: materiamedica@btinternet.com
}

The theme of this review is to summarize the evolving processes in cardiovascular drug discovery and development within a large pharmaceutical company. Emphasis is placed on the contrast between the academic and industrial research operating environments, which can influence the effectiveness of research collaboration between the two constituencies, but which plays such an important role in drug innovation. The strategic challenges that research directors face are also emphasized. The need for improved therapy in many cardiovascular indications remains high, but the feasibility in making progress, despite the advances in molecular biology and genomics, is also assessed.

\begin{abstract}
In a recent article on our understanding of the evolution of coronary artery disease and myocardial infarction and its treatment, it was concluded (Mabel and Braunwald 2012) that "the pathways of discovery, innovation and therapeutic advancement in cardiovascular science and medicine over the past two centuries have been truly remarkable." They describe the impressive decline in deaths from cardiovascular disease in relation to scientific advances between 1950, when it was approximately 450 per 100,000 of the population, to about 100 per 100,000 by 2010 (see Fig. 1). Whereas many clinical advances contribute to this impressive decline, the investigators emphasize the importance of $\beta$-blocking therapy, HMG Co-A reductase inhibition as well as the introduction of novel antihypertensive agents in the context of
\end{abstract}

the national high blood pressure education program. Despite these beneficial outcomes, the prevalence of cardiovascular disease remains persistently high, partly caused by concomitant diseases such as diabetes mellitus and obesity as well as congestive heart failure. Furthermore, the impressive reduction in mortality rates for myocardial infarction made such patients to live longer, but subsequently develop heart failure, which has a worse prognosis than myocardial infarction. This role of innovative drugs is further supported by the masterly analysis by Comroe and Dripps (1976) in which they identified the major advances in cardiopulmonary medicine in the last $30 \mathrm{yr}$. Of 529 key articles, $41 \%$ were judged to be essential for later clinical advances, but were not clinically oriented at the time the work was performed. The scientists

Editors: Margaret Buckingham, Christine L. Mummery, and Kenneth R. Chien

Additional Perspectives on The Biology of Heart Disease available at www.perspectivesinmedicine.org

Copyright (C) 2014 Cold Spring Harbor Laboratory Press; all rights reserved; doi: 10.1101/cshperspect.a014092

Cite this article as Cold Spring Harb Perspect Med 2014;4:a014092 
G. Gromo et al.

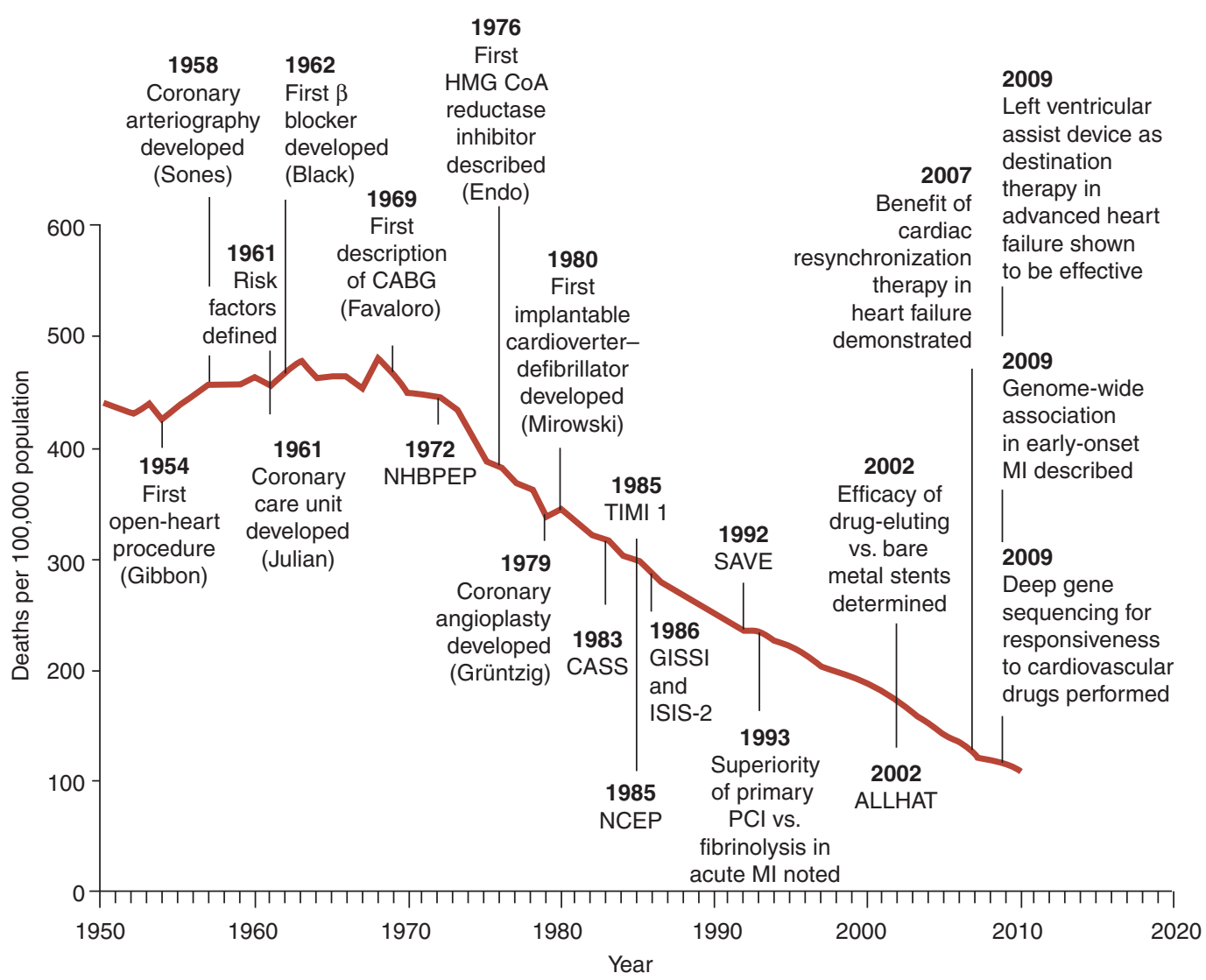

Figure 1. Decline in deaths from cardiovascular disease in relation to scientific advances. (From Mabel and Braunwald 2012; reproduced, with permission.)

responsible for these key articles sought knowledge for the sake of knowledge. However, $61.7 \%$ described basic research whose goal was clinically oriented. Of the top 10 clinical advances in this field, they identified drug treatment of hypertension, medical treatment of coronary insufficiency, and oral diuretics as being major advances. Despite these previous improvements in drug therapy, improvements in treating cardiovascular diseases such as heart failure and cardiac arrhythmias are still required.

\section{PHARMACEUTICAL RESEARCH AND DEVELOPMENT IN THE 21st CENTURY}

The traditional approach to discovering novel medicines relied on effective scientific collaboration between medicinal chemists and bio- scientists within the context of a commercial organization, whose objective was to reward investors by selling medicines globally. This traditional model has been radically changed in the 21 st century. Clearly, the research culture differs markedly from that of academic research. It is easy to understand why academic scientists who undertake commercial drug research often have initial difficulties in adapting to their new operating environment. The key features of this new operating environment are captured in the force diagram illustrated in Figure 2. The apex of the force diagram comprises payers that is, government or insurers, responsible for looking after the patients' therapeutic treatments. The payers' objective is to reduce drug costs yet ensure that significantly improved treatments are available. For example, Medicare 


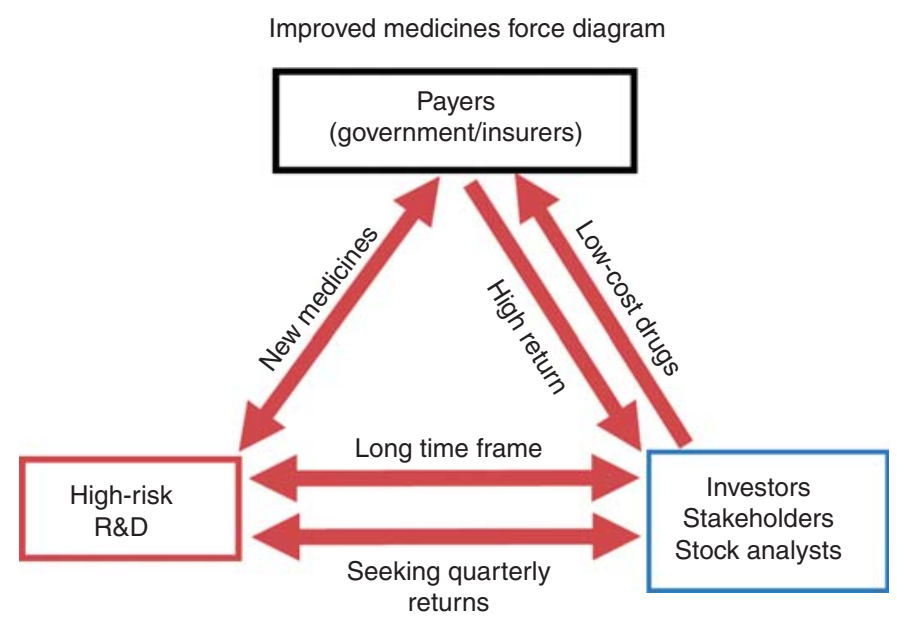

Figure 2. This diagram depicts the competing needs and objectives of the constituencies committed to therapeutics (payers), drug hunters in $\mathrm{R} \& \mathrm{D}$, and investors seeking financial returns.

requires that a new treatment for chronic kidney disease should delay the onset of end-stage renal disease by at least $2 \mathrm{yr}$ to pay a premium price. The investors' (bottom right of diagram) objective is to maintain a good financial return on their investment, preferably on an annually increasing return—although company decisions reported on a quarterly basis do strongly influence share price. The paradox is that effective research and development (left arm of diagram) leading to the introduction of improved therapy is extremely difficult, characterized by frequent failures in development over the 10- to 12 -yr period, which involves discovery/clinical development and submission to regulatory bodies. Thus, senior directors of research within pharmaceutical companies are faced with increasingly challenging strategic decisions when selecting and approving research proposals prepared by chemists and bioscientists within the company. Their novel ideas can have a protean origin, and currently much emphasis is placed on academic/industrial collaborative research projects, termed "translational research," as a source of improved medicines. Scrutiny of previous drug discovery indicates that translational research has been practiced in one form or another for the last $100 \mathrm{yr}$, and perhaps the best example is Withering's isolation and purification, followed by evaluation, of extracts of digitalis purpurea for treating ascites in 1785 (Withering 1785). The fact is that, undoubtedly, academic research provides the fountain for new scientific concepts, but their exploitation for identifying improved medicines follows a tortuous and unpredictive path in which serendipity continues to make a contribution. The strengths and pitfalls of academic/industrial collaboration have recently been reviewed, and it has been concluded that often the principles and practice for effective collaboration are neglected by individual institutions (Chin-Dusting et al. 2005). The research portfolio of an individual pharmaceutical company will reflect the resultant of those forces illustrated in Figure 2. The research director has to make judgments about research proposals such that the portfolio represents an acceptable balance between attractive, but speculative research proposals where there is no prior evidence of therapeutic efficacy (often termed first-in-class), and proposals in which the effectiveness of the therapeutic action is established, but the leading compounds have serious drawbacks in clinical practice (often termed fast-following projects). It must be emphasized that this latter research differs significantly from the so-called "me-too" projects, which fail to articulate any desirable therapeutic improvement. There is an unfortunate tendency among constituencies who independently eval- 
G. Gromo et al.

uate newly introduced drugs, many of which contain innovative improvements, to call them "me too," without defining the term, which underestimates the clinical value of the treatment.

\section{PORTFOLIO DECISIONS}

Against this background, what is the actual process by which strategic portfolio decisions are made? The process within the F. Hoffmann-La Roche company has been described in some detail in a previous publication and is summarized in Figure 3 (Knowles and Gromo 2003). It shows three levels of interaction: first, between the company board members and the research director, which should result in selection of disease areas that the research department should focus on. The second level is the interaction between the research director and both the senior scientific managers and scientists from different disciplines. Hopefully, the resultant of these interactions will lead to an outcome not only of an improved medicine, but the longterm commercial viability of the company.

In essence, each research director develops his or her own set of criteria, which should culminate in a risk-adjusted benefit appraisal. Each research director will also have his or her own set of criteria, which are weighted by different factors. An interesting example is that proposed by Black (2010) (see Table 1) who was awarded the Nobel Prize for his discovery both of $\beta$ blockers for angina pectoris and histamine antagonists for peptic ulcer. Such criteria provide a useful framework for constructive debate about research proposals, with the various scientific disciplines illustrated in Figure 3.

Perhaps Black's most important caveat is the need to avoid "wishful thinking," as captured by him in the phrase "wouldn't it be nice if. ..." An alternative example of the criteria sometimes used within F. Hoffmann-La Roche is illustrated in Table 2. It must be emphasized that such formats do not provide answers, but do help avoid

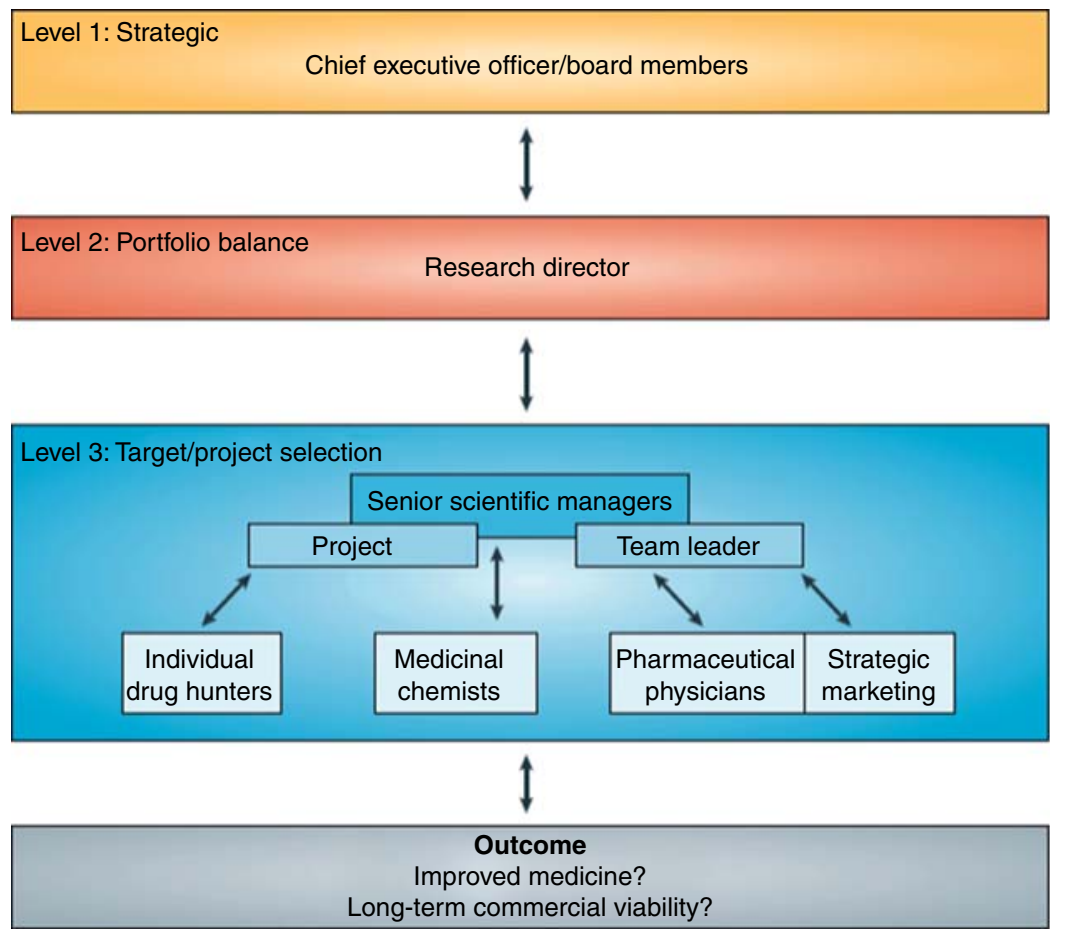

Figure 3. Diagram showing the interaction between different groups accountable for target selection. (From Knowles and Gromo 2003; reproduced, with permission.) 
Table 1. Black project-evaluation criteria (data based on Black 2010)

1. I must have evidence, before I start, that the desired selectivity is capable of being expressed by a drug. There may be empirical evidence that other drugs are already known to possess that selectivity and then there is no issue to settle. However, when the desired selectivity is new, then, unless there is evidence of the biochemical differentiation that will allow the selectivity to be expressed, the project is likely to be based on mere wishful thinking and probably doomed from the start.

2. There must be an explicit chemical starting place. Medicinal chemists must have a molecular template with the command "Begin here." The chemical template may be an already known drug or it may be a natural, physiologically important, molecule or even, today, a lead generated by random screening - but they have to start somewhere.

3. There has to be a biological measurement, or bioassay, which can measure the specific property imagined to underlie the intended selectivity - in my experience, a functional bioassay is always preferable to a surrogate marker.

4. Before I start, I have to be able to envisage how I will be able to show in man that the drug has the same basic actions as I would have found in the laboratory.

5. I have to have some disease in mind in which it would be logical to evaluate the new drug's properties.

6. I or one of my colleagues must feel passionate about the project-drug research programs can go through long periods, as much as $4-5 \mathrm{yr}$, when little progress seems to be happeningthen passionate conviction is what keeps you going.

7. Finally, there must be a reasonable likelihood of adequate funding to complete the project.

the more obvious pitfalls encountered in occasionally overenthusiastic research proposals. In evaluating speculative "first-in-class" research proposals, the director has to sail between the Scylla of overenthusiastic acceptance and the Charybdis of excessive negative critical apprais-
Challenges in Drug Discovery and Clinical Trials

al. There are several examples of subsequently successful first-in-class medicines being initially rejected. The discovery of the first ACE inhibitor by Cushmann and Ondetti at the Squibb Institute for Medical Research was initiated by discussions with their pharmacology consultant Professor Sir John Vane, who thought that inhibition of such an enzyme might have therapeutic possibilities. At that time, many cardiovascular clinical scientists doubted the importance of the renin-angiotensin system in human hypertension, but this view was refuted with the discovery of the first parenterally active peptide inhibitor, teprotide, in 1970, which showed useful blood pressure-lowering activity given by the parenteral route. No oral activity could be detected among 2000 analogues and, as Ondetti

Table 2. Hoffmann-La Roche project-evaluation criteria

\section{Target confidence}

Extent to which current evidence supports:

Biological plausibility

Correlation to animal models and throughput

Effectiveness in man

Feasibility

Technical feasibility:

Extent to which the project is technically feasible

Consider target class and drugability; setting up assays and HTS

\section{Compound potential}

Extent to which evidence reveals no deficiencies related to the chemical entity itself

If there is no evidence, consider quality/potential risk of the compound class/lead series

\section{Achieving milestone}

Extent to which current knowledge about the project does not cause concern about its ability to meet the next milestone on time

\section{Effort TPP}

Extent to which evidence supports a prediction that the TPP will be proven early in development

Consider when critical data will become available

\section{Differentiation}

Extent to which evidence supports differentiation from existing therapies and projects in development 


\section{G. Gromo et al.}

subsequently recorded, "as usual in drug research, the lack of results and pressing needs of other projects dictated that we put aside our research on ACE inhibition" (Cushmann and Ondetti 1999). The Head of Pharmacology at Squibb at that time (Dr. Goldberg) recollected that the VP of Research instructed him not to discuss anything about the ACE work (M Goldberg, pers. comm.).

Cushmann persisted, and 1 yr later captopril was discovered and marketed in 1978. This account, which is described in detail elsewhere (Fitzgerald 2001), is quoted because first it gives an elegant example of the influence of academic/industrial collaboration, and second because it illustrates the difficulty that senior management often has in supporting speculative research projects. Clearly much depends on the judgment of the research director and his or her management team. Examples of highly successful research directors include Dr. Paul Janssen of the Janssen company (40 marketed products discovered between 1953 and 1984), Sir David Jack of Glaxo (discovery of first inhaled steroids and long-acting $\beta$ stimulants for asthma; antimigraine treatments), and Garnett Davey of Imperial Chemical Industries ( $\beta$ blockers, fibrates, antiestrogens, novel anesthetics). One might speculate that the environment in which these successful research directors operated did not have the kinds of pressures summarized in the force diagram (Fig. 2), although some other pressures may have had a role to play. Undoubtedly, the role of the research director in a pharmaceutical company today is extremely demanding. The judgments to be made can be illustrated by the uncertainty map (Fig. 4A), which depicts the vertical axis increasing uncertainty about ends or targets and the horizontal axis increasing uncertainty about means of achieving the target; the third dimension is the time taken to achieve the goal. The director's portfolio can be placed in one of the four squares, where square one shows high uncertainty both about means and ends, whereas square four shows much lower uncertainty about both ends and means, but it is likely that there are many competitive compounds or products in square four as opposed to square one. Predictably, the portfolio should try to avoid research projects that are either in square two or square three. Hence, the judgment needed based on the uncertainty force diagram (Fig. $4 \mathrm{~B}$ ) relates to assessing first the means - can I discover it?; second, the ends-is there a need for an improved medicine?; and, finally-how much time will it take to achieve these ends? The spectrum of the drug portfolio can be captured in the technology curve, which relates the time of inception of the therapeutic class to the potentially improved technological performance. At the inception of a research project, which is speculative, the performance is highly uncertain, whereas if there are defensible ideas about improvement for differentiation, the prospects of success are so much higher. In the current

\section{A}

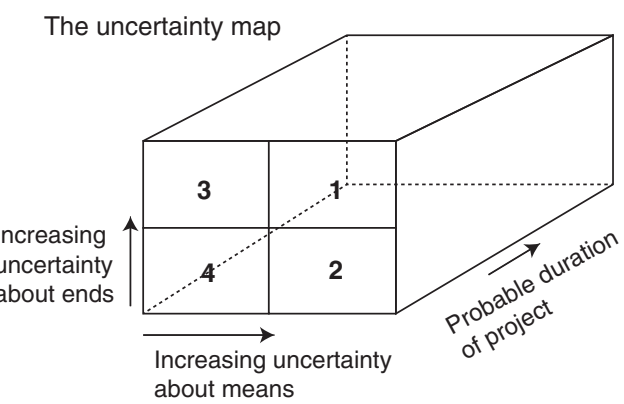

B

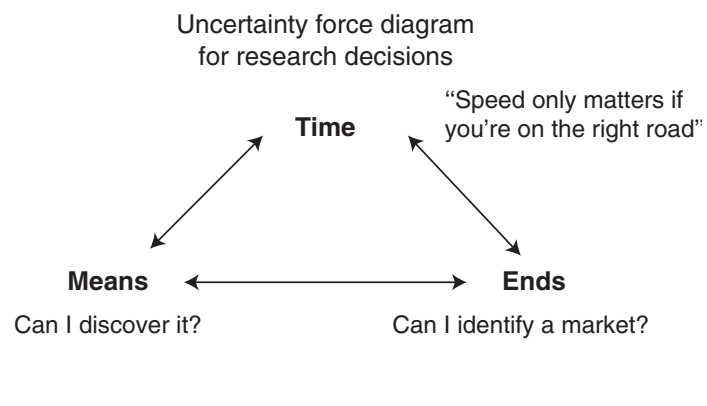

Figure 4. Factors in assessing a project late in the level of uncertainty about the therapeutic target (ends) and the type of drug effect desired (means) in relation to the probable project timelines (duration). ( $A$ ) The uncertainty map, and $(B)$ the uncertainty force diagram for research decisions. 
environment, there is little to be gained by doing "me-too" research. Underlying these portfolio elements is the potential chance of a paradigm shift in technological performance, of which the current progress in stem cell research may be a useful example.

\section{ASPECTS OF DRUG DEVELOPMENT}

The complex series of steps involved in implementing a research project is widely understood. Apart from identifying the specificity and relative selectivity for the target of the candidate compound, the key determinants of progress are the desired pharmacokinetic properties and the absence of unwanted cardiovascular effects, especially on cardiac conduction and blood pressure. The timely evaluation of the hemodynamic and electrophysiological effects of candidate compounds is one of the critical steps in deciding the potential benefit/ risk of a compound (Ritter 2012). An exciting new field of study is the application of human pluripotent stem cell-derived cardiomyocytes (hPSCCM), which may predict the effects of compounds on both contractile function and electrophysiological effects in atrial and pacemaker function. These stem cells may also be used to test for acute cardiotoxicity of compounds (Foldes et al. 2011; Matsa et al. 2011), permitting the early elimination of compounds with undesirable cardiac effects. Such studies still do not supplant the need for careful clinical studies on possible drug effects on cardiac conduction. Furthermore, the preclinical in vivo studies are not designed to reflect the clinical situation where a novel compound may be added to current established therapy.

It is now clear that applying systems biology of in silico models to cardiac electrophysiology has considerable potential for evaluating drug effects on multiple ion channels. A practical example is the demonstration that the antianginal drug ranolazine, which causes significant binding to cardiac HERG channels, does not induce torsades de pointes because it has additional multiple effects on other ion channels, so the net effect is to prevent unwanted QT prolongation (Noble and Noble 2006; Mirams et al.
2011). A recent U.S./EU regulatory-sponsored workshop made recommendations as to how computational models could make an important contribution to the preclinical evaluation of the net effects of either candidate compounds or established, but withdrawn compounds thought to be proarrhythmic. A classical example is that of verapamil, which causes dose-dependent QT prolongation, but because of its multiple cardiac ion channel effects does not cause torsades de pointes (Fletcher et al. 2011).

\section{IN VIVO MODELS}

The main cardiovascular therapeutic diseases studied by the pharma industry include congestive heart failure, cardiac ischemia secondary to atherothrombosis, cardiac dysrhythmias, and hypertension. There is a longstanding tradition of in vivo models for these diseases, but their predictive value has many shortcomings. Unavoidable shortcomings are the influence of species differences, or the testing in experimental animal models that have either no longstanding cardiac pathology or the absence of common concomitant diseases such as diabetes, as well as testing the drug as if it were going to be used as first line rather than on top of standard treatment. In addition, there may be hurdles attributable to the assumptions made by basic and clinical scientists as to the nature of the pathophysiological process.

A current example is in the field of cardioprotection and prevention of the downstream consequences of myocardial ischemia and reperfusion injury. Undoubtedly, there is a huge unmet medical need, which has been the stimulus for research in this field for the past $30 \mathrm{yr}$. The nature of the targets to be modulated remains debatable, possibly because of the complexity of the pathophysiological targets (Eltzschig and Eckle 2011). Despite these drawbacks, many research companies are engaged in finding novel compounds, which modulate a range of target mechanisms both experimentally and clinically (see Table 3 ). Despite the advances in mechanistic concepts, the decision to engage in this therapeutic target is not only high risk, but also rather long term. The potential ambi- 


\section{G. Gromo et al.}

Table 3. Examples of current approaches to modulating ischaemia reperfusion injury

\begin{tabular}{|c|c|c|c|}
\hline Intervention & Target & Potential downside & Stage \\
\hline TAK-242 & Inhibition of TLR4 & $\begin{array}{l}\text { Immune suppression, } \\
\text { worsening of bacterial } \\
\text { infections }\end{array}$ & $\begin{array}{l}\text { Phase } 2 \text { clinical trial in } \\
\text { acute respiratory failure; } \\
\text { preclinical studies in } \\
\text { ischemia and } \\
\text { reperfusion }\end{array}$ \\
\hline $\begin{array}{l}\text { T-cell-based } \\
\text { approaches }\end{array}$ & $\begin{array}{l}\text { Suppression of } \gamma \delta-\mathrm{T} \text { cells; } \\
\text { expansion of Treg cells }\end{array}$ & Unclear & Preclinical \\
\hline $\begin{array}{l}\text { Fibrinogen split } \\
\text { product } \mathrm{B} \beta_{15-42}\end{array}$ & Unclear & Unclear & Phase 2 clinical trial \\
\hline Cyclosporine & Inhibition of apoptosis & $\begin{array}{l}\text { Immune suppression; } \\
\text { worsening of bacterial } \\
\text { infection }\end{array}$ & Phase 2 clinical trial \\
\hline Chloramphenicol & Activation of autophagy & $\begin{array}{l}\text { Bone marrow toxicity } \\
\text { (bone marrow } \\
\text { suppression or aplastic } \\
\text { anemia) }\end{array}$ & $\begin{array}{l}\text { Preclinical (large animal } \\
\text { study) }\end{array}$ \\
\hline PHD inhibitors & $\begin{array}{l}\text { Inhibition of the oxygen- } \\
\text { sensing PHD enzymes } \\
\text { resulting in HIF stabilization }\end{array}$ & Unclear & $\begin{array}{l}\text { Phase } 2 \text { clinical trial in } \\
\text { renal anemia; preclinical } \\
\text { studies in ischemia and } \\
\text { reperfusion }\end{array}$ \\
\hline $\begin{array}{l}\text { Ischemic } \\
\text { preconditioning }\end{array}$ & $\begin{array}{l}\text { Multiple (for example, } \\
\text { adenosine signaling, HIF } \\
\text { stabilization and attenuation } \\
\text { of inflammation) }\end{array}$ & Unclear & Phase 2 clinical trial \\
\hline $\begin{array}{l}\text { Ischemic } \\
\text { postconditioning }\end{array}$ & Multiple & Unclear & Phase 2 clinical trial \\
\hline $\begin{array}{l}\text { Remote ischemic } \\
\text { conditioning }\end{array}$ & Multiple & Unclear & Phase 2 clinical trial \\
\hline Nitric oxide (NO) & Multiple & $\begin{array}{l}\text { Elevation of } \\
\text { methemoglobin }\end{array}$ & Phase 2 clinical trial \\
\hline Apyrase & $\begin{array}{l}\text { ATP breakdown (attenuation } \\
\text { of ATP signaling and } \\
\text { promotion of adenosine } \\
\text { generation and signaling) }\end{array}$ & Unclear & Preclinical \\
\hline Nucleotidase & $\begin{array}{l}\text { AMP conversion to adenosine; } \\
\text { enhanced adenosine } \\
\text { generation and signaling }\end{array}$ & Unclear & Preclinical \\
\hline $\begin{array}{l}\text { Regadenoson, } \\
\text { ATL146e }\end{array}$ & $\begin{array}{l}\text { Specific adenosine receptor } \\
\text { agonists targeting Adora } 2 \mathrm{a}\end{array}$ & Unclear & Phase 1 trial ongoing \\
\hline Bay 60-6583 & $\begin{array}{l}\text { Specific adenosine receptor } \\
\text { agonist targeting Adora2b }\end{array}$ & $\begin{array}{l}\text { Sickling of red blood cells } \\
\text { in individuals with } \\
\text { sickle cell disease }\end{array}$ & Preclinical \\
\hline $\begin{array}{l}\text { Inhibitors of } \\
\text { miR-92a }\end{array}$ & Promotion of angiogenesis & Unclear & Preclinical \\
\hline $\begin{array}{l}\text { Activators of miR- } \\
499 \text { or miR- } 24\end{array}$ & Inhibition of apoptosis & Unclear & Preclinical \\
\hline
\end{tabular}

From Eltzschig and Eckle 2011; reproduced, with permission. 
guities in the field of ischemic reperfusion injury have been critically appraised by Sobel, whose suggestion that injury to cardiomyocytes secondary to ischemia would still occur in the absence of reperfusion is possibly based on an erroneous assumption that the two consequences are related (Sobel and Tarikuz Zaman 2011, 2012).

The target of congestive heart failure shares many similar features of exciting progress in the understanding of the tissue abnormalities at the cellular level, but an uncertain relationship to the specific clinical phenotype of congestive heart failure. These examples are cited to illustrate the generic challenges facing cardiovascular research scientists in pharmaceutical companies trying to find improved treatments for widespread cardiovascular diseases. This may explain why many recently introduced compounds have been either antithrombotics or lipoprotein modulators designed to reduce the complications of atherothrombosis. Such targets are characterized by greater predictive value of in vivo animal models and more firmly established mechanistic hypotheses. There still remain exciting, but speculative atherothrombotic targets such as the recent proposal for IL-6 inhibitors (IL6R Genetics Consortium Emerging Risk Factors Collaboration 2012). It must be accepted that there are few models of human disease in animals that reproduce the key elements of human pathophysiology. Models can reflect a particular feature of a disease, but most human diseases have a complex multifactorial etiology. Being critical of the relationship between models, however created, and the human disease is essential. Failure to do so may explain some of the disappointing results in subsequent clinical trials.

Although the above comments appear somewhat pessimistic, the current upsurge in cardiovascular molecular biology may provide better predictive in vivo models, which should be based on primarily mechanistic targets rather than a model of the disease. The creation of specific genetic models of disease, particularly in mice, such as the humanized mouse model to evaluate a target hypothesis, should be of considerable help. Such research will require ac-
Challenges in Drug Discovery and Clinical Trials

ademic/industrial collaboration to foster multidisciplinary approaches.

A final consideration is the increasing ethical concerns about animal testing in general, on which the regulatory bodies are placing significant emphasis through their 3Rs strategy, that is, reduction of animal use; refinement to preserve animal well-being; and replacement of animals by cells and lower organisms. These concerns are mainly addressed to safety testing for regenerative medicine advances (Robinson 2011). The regulatory-based initiatives are constructive and raise the possibility of using novel in vitro models of disease to replace, or at least reduce, in vivo studies.

Previous experience within the F. Hoffmann-La Roche company provides practical examples of the shortcomings of in vivo models. The discovery of endothelin and its receptors in the 1980s provided an exciting speculative target for several cardiovascular diseases (Chabrier and Braquet 1990). A research program leading to the discovery of an orally active selective receptor antagonist, bosentan, which provided positive data in a range of in vivo cardiovascular models, supported the decision to proceed to phase II trials in congestive heart failure. Unfortunately, the clinical trials indicated variable and unpredictable effects (Sütsch et al. 1998; Teerlink 2002). Finally, efficacy was shown in idiopathic pulmonary hypertension, which was not the original target profile (Clozel et al. 1997; Thorin and Clozel 2010). Because this indication was not regarded as commercially attractive, bosentan was licensed out to a small biotech, Actelion, who succeeded in turning it into a highly successful project, mainly by expanding the pulmonary arterial hypertension market beyond the original boundaries assessed by big pharma.

A project with great promise was mibefradil (Posicor), which was a first-in-class novel selective blocker of the low-voltage-activated (T-type) calcium channel, with potential applications in hypertension, angina pectoris, and congestive heart failure because of its ability to selectively dilate coronary and peripheral vessels with no negative inotropic actions. It was discovered in 1987 and subsequently shown to be effective in all three indications. It also caused 
marked inhibition of CYP3A4 drug-metabolizing enzyme, leading to concerns about the potentiation of coadministered agents, especially HMG-CoA reductase inhibitors. The compound was approved by the FDA in June 1997, but was subsequently withdrawn because of concerns about potential dangers arising from the drug-drug interactions (Billups and Carter 1998). This project exemplifies the complexities in strategic assessment of benefit/risk of a novel compound. The benefit/risk assessment relies finally on rather subjective opinions that will differ markedly within different constituencies, both within the company and the regulatory agencies, although the latter have the final decision on whether to withdraw the drug or not. Lessons learned from this experience include a research strategy of taking interesting novel compounds forward from more than one chemical series to reduce chances of unanticipated negative effects on either cardiovascular function or alterations in drug-metabolizing enzymes.

An additional important element in the benefit/risk assessment is ensuring a constructive dialogue with the marketing department within a pharmaceutical company. Understandably its priority is to ensure appropriate commercial exploitation of marketed compounds. Such a dialogue can, on occasion, be difficult for a number of reasons including, perhaps, unrealistic expectations in the predictions of speculative research projects, important differences both in value systems and the understanding of research and development (R\&D), as well as conflicting priorities and time frames. It is not our intention to expand on the tasks of the $\mathrm{R} \& \mathrm{D} /$ marketing interface, but a constructive relationship is vital for project survival. This aspect clearly distinguishes industrial from academic research. It is important for academic/ industrial collaborations to accept that the opinion of strategic marketing is a major factor in selecting future research projects.

\section{CLINICAL TRIALS}

In establishing candidate drug efficacy, this is the stage where clinical scientists play a key role in the project's success or failure. Currently, clinical trials are classified by the terms phase I, IIa, IIb, III, and IV. Such terms do not necessarily explain which scientific question is being addressed at each stage in relationship to the target concept. Initial human exposure (phase I) may be in either healthy volunteers or patient volunteers, particularly in the case of oncology products, although this trend is rapidly expanding into some metabolic diseases such as diabetes. The development of specific monoclonal antibodies requires an approach related to the cellular target, usually a cell surface receptor. The emerging genomic and biomarker technologies are leading to an increasing impact on the design of clinical trials. In a recent survey of 21 pharmaceutical companies by the Tufts Centre for the Study of Drug Development, it was found that half of a company's pipeline projects would be associated with biomarkers, but only $10 \%$ had identified specific large patient populations or companion diagnostics (Zuckerman and Milne 2012). The F. Hoffmann-La Roche R\&D culture places a major emphasis on biomarker research and companion diagnostics, particularly for the characterization of the effects of compounds in the current pipeline. Notably, $5 \%$ of responders in the Tufts survey indicated the use of personalized medicine approaches for cardiovascular indications, although in diseases with complex pathophysiological processes such as atherosclerosis, the personalized medicine approach faces higher hurdles than in oncology where a single nucleotide mutation such as BRAF V600 can be targeted in melanoma (Ascierto et al. 2012).

Genomic biomarker studies may involve a range of characteristics including expression, function, or regulation of a gene, single nucleotide polymorphisms (SNPs), methylation, and variations in the number of gene copies. In determining an individual's response to a drug treatment, measurements may be made of the expression of gene, gene function, RNA, or miRNA, reflecting either aspects of disease diagnosis or the effects of the intervention. Characterization of an individual patient's genetic trait reflects the possible effect of treatment therapy. In a recent overview of this field, it was emphasized that classifying trial partici- 
pants based on genomic profiles of responders to those of nonresponders can be associated with a high misclassification rate in distinguishing susceptible and nonsusceptible patients (Saha et al. 1996; Agerholm-Larsen et al. 2000). It was emphasized that a large sample size may be needed to ensure detection of a significant number of biomarkers, and a significant number of susceptible subjects to permit biomarker validation (Lyn and Chen 2012). The development of statistical algorithms requires the recruitment of a larger number of patients, which is an aspect that can be overlooked by enthusiastic project teams. It would seem that the validation of genomic biomarkers is more complex than many involved in drug development appreciate. The genome-wide association studies arising from the international human Hapnap project reveal a startling degree of structural genomic variation, which, although of fundamental scientific importance, are unlikely to lead to the identification of genetic causes of common cardiovascular conditions (Hardy and Singleton 2009). In a recent critical evaluation of pharmacogenetic biomarkers in cardiovascular therapeutics, Ong et al. (2012) concluded that "the greatest obstacle to clinical implementation of cardiovascular pharmacogenetics may be the lack of both reproducibility and agreement about the validity and utility of the findings."

In establishing proof-of-concept within a pharmaceutical company, one of the most im- portant tasks is establishing proof of efficacy with an acceptable risk/benefit profile for the candidate compound. The outcome of a proofof-concept study is awaited with ill-suppressed anxiety at all levels and most functions within the organization. As illustrated in the force diagram (Fig. 2), the external investors anxiously await such news, which in turn determines the short-term share price of the company. As a consequence, there is sustained pressure on the clinical trials scientists to obtain a valid answer to the phase II trial with the shortest possible time. Such pressure can lead to unintended consequences! There are some difficulties with the classical well-established phase II protocols. For example, there are increasing exclusion criteria in the phase II trials, so that these studies do not reflect the real world. Patients recruited into phase III trials may be very different from those studied in phase II. This may contribute to the high attrition rate of phase III trials. Optimizing the design of phase III trials has to include variability in patient populations and therefore phase II trials should contain much more representative patients. To address the question of variability in individual patient responses, model-based analysis is used, which attempts to relate dose to exposure, exposure to pharmacodynamic event, and from biomarker response to a relevant clinical endpoint (see Fig. 5). The use of pharmacometrics can markedly enhance the accurate profiling of a new compound. In a recent review, Jonssen

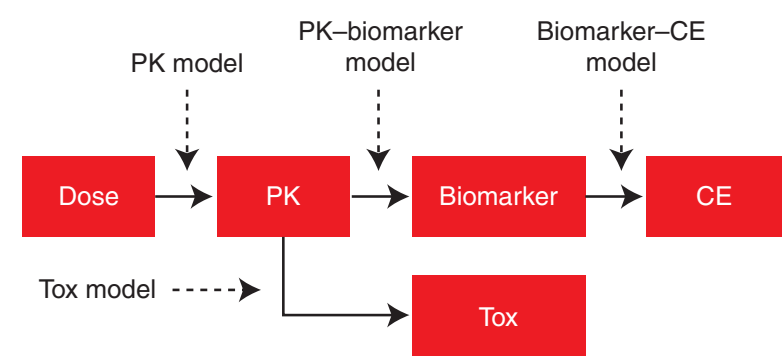

Figure 5. Model-based analysis of the design of proof-of-concept trials. The model for the mechanistic pathway of drug response consists of: a pharmacokinetic (PK) model for the dose-exposure relationship, a pharmacokinetic biomarker model for the exposure-biomarker relationship, a biomarker clinical endpoint (CE) model for the biomarker-clinical endpoint relationship, and a pharmacokinetic toxicity (Tox) model for the exposure-toxicity relationship. 
and Sheiner showed that model-based analysis may yield greater statistical power than hypothesis testing at any $P$ value. The result, an increasingly popular approach, is to use adaptive clinical trial designs (Lai et al. 2012). This has been defined as "a clinical study design that uses accumulating data to decide how to modify aspects of the study as it continues, without undermining the validity and integrity of the trial." It is not our intention to discuss the range of possibilities in adaptive trial design because there are important differences of opinion that exist between statisticians, which includes the interesting application of Bayesian study designs (Chevret 2011). The principal point to be made is that it is now possible to improve markedly the timelines for establishing proof-of-concept of a novel compound without necessarily losing scientific validity with, however, the caveat that the infrastructure required for agile adaptive designs may represent an added burden for the development structure because data management and statistical calculation of laboratorybased measurements need to be turned around in a significantly shorter time than what is "classical" in most companies. Many additional aspects of clinical trial design are covered in the article by Collins (2014).

\section{CONCLUSION}

The purpose of this review is to provide scientists, who have an interest in discovering improved cardiovascular therapies, a perspective on the pharmaceutical $\mathrm{R} \& \mathrm{D}$ process. The challenges facing senior directors who lead different departments within a large complex institution in a pharmaceutical company are briefly illustrated with emphasis on the complexities and uncertainties in selecting projects with potentially improved efficacy. These uncertainties have certain features in common in selecting academic scientific projects, which require funding in a competitive environment. Emphasis has been placed on the intense pressures on decision makers within companies caused by the conflicting aims of the different constituencies, which determine the nature of the current operating environment. The dual demands of finding both innovative improved cardiovascular drugs in the briefest possible time frame, without impairing scientific validity, distinguishes profoundly the difference between academic and industrial pharmaceutical research. An appreciation of such factors is essential for constructive academic/industrial collaboration for the future.

\section{REFERENCES}

${ }^{*}$ Reference is also in this collection.

Agerholm-Larsen B, Nordestgaard BG, Tybjaerg-Hansen A. 2000. ACE gene polymorphism in cardiovascular disease: Meta-analyses of small and large studies in whites. Arterioscler Thromb Vasc Biol 20: 484-492.

Ascierto PA, Kirkwood JM, Grob JJ, Simeone E, Grimaldi AM, Maio M, Palmieri G, Testori A, Marincola FM, Mozzillo N. 2012. The role of BRAF V600 mutation in melanoma. J Transl Med 10: 85.

Billups SJ, Carter BL. 1998. Mibefradil: A new class of calcium-channel antagonist. Ann Pharmacol 32: 659-671.

Black J. 2010. A life in new drug research. Brit J Pharmacol 160: S15-S25.

Chabrier PE, Braquet P. 1990. Endothelin. Hormone Res 34: $169-174$.

Chevret S. 2011. Bayesian adaptive clinical trials: A dream for statisticians only? Stat Med 31: 1002-1013.

Chin-Dusting J, Fitzgerald D, Jennings G. 2005. Finding improved medicines: The role of academic-industrial collaboration. Nat Rev Drug Disc 4: 891-897.

Clozel JP, Ertel EA, Ertel SI. 1997. Discovery and main pharmacological properties of mibefradil (Ro 40-5967), the first selective T-type calcium channel blocker. J Hypertens Suppl 15: S17-S25.

* Collins. 2014. Cold Spring Harb Perspect Med doi: 10.1101/ cshperspect.a.

Comroe JH, Dripps RD. 1976. Scientific basis for the support of biomedical science. Science 192: 105-111.

Cushmann DW, Ondetti MA. 1999. Design of angiotensin converting enzyme inhibitors. Nat Med 5: 11101112.

Eltzschig HK, Eckle T. 2011. Ischaemia and reperfusionFrom mechanism to translation. Nat Med 17: 13911401 .

Fitzgerald JD. 2001. Trails of discovery: A close call: The discovery of the ACE inhibitors. Dialog Cardiovasc Med 6: $38-42$.

Fletcher K, Shah RR, Thomas A, Tobin F, Rodriguez B, Mirams GR, Saiz J, Noble D. 2011. Novel approaches to assessing cardiac safety-Proceedings of a workshop: Regulators, industry and academia discuss the future of in silico cardiac modelling to predict the pro-arrhythmic safety of drugs. Drug Safety 34: 439-443.

Foldes G, Mioulane M, Wright JS, Liu AQ, Novak P, Merkely B, Gorelik J, Schneider MD, Ali NN, Harding SE. 2011. Modulation of human embryonic stem cell-derived car- 
diomyocyte growth: A testbed for studying human cardiac hypertrophy? J Mol Cell Cardiol 50: 376-376.

Hardy J, Singleton A. 2009. Genome-wide association studies and human disease. N Engl J Med 360: 1759-1768.

IL6R Genetics Consortium Emerging Risk Factors Collaboration. 2012. Interleukin-6 receptor pathways in coronary heart disease: A collaborative meta-analysis of 82 studies. Lancet 379: 1205-1213.

Knowles J, Gromo G. 2003. Target selection in drug discovery. Nat Rev Drug Disc 2: 63-69.

Lai TL, Lavori PW, Shih MC. 2012. Adaptive trial designs. Аnnu Rev Pharmacol Toxicol 52: 101-133.

Lyn WJ, Chen JL. 2012. Biomarker classifiers for identifying susceptible subpopulations for treatment decisions. Pharmacogenomics 13: 147-157.

Mabel EG, Braunwald E. 2012. A tale of coronary artery disease and myocardial infarction. $N$ Engl J Med 366: $54-62$.

Matsa E, Rajamohan D, Dick E, Young L, Mellor I, Staniforth A, Denning C. 2011. Drug evaluation in cardiomyocytes derived from human-induced pluripotent stem cells carrying a long QT syndrome type 2 mutation. Eur Heart J 32: 952-962.

Mirams GR, Cui Y, Sher A, Fink M, Cooper J, Heath BM, McMahon NC, Gavaghan DJ, Noble D. 2011. Stimulation of multiple ion channel block provides improved early prediction of compounds' clinical torsadogenic risk. Cardiovasc Res 91: 53-61.

Noble D, Noble PJ. 2006. Late sodium current in the pathophysiology of cardiovascular disease: Consequences of sodium-calcium overload. Heart 92: 1-5.

Ong FS, Deignan JL, Kuo JZ, Bernstein KE, Rotter JI, Grody WW, Das K. 2012. Nickel utility of pharmacogenetic biomarkers in cardiovascular therapeutics: A challenge for
Challenges in Drug Discovery and Clinical Trials

clinical implementation. Pharmacogenomics 13: 465475.

Ritter JM. 2012. Cardiac safety, drug-induced QT prolongation and torsades de pointes (TdP). Br J Clin Pharmacol 73: $331-333$.

Robinson R. 2011. 3Rs of animal testing for regenerative medicine products. Science Trans Med 3: 1-3.

Saha N, Talmud PJ, Tay JS, Humphries SE, Basair J. 1996. Lack of association of angiotensin-converting enzyme (ACE). Gene insertion/deletion polymorphism with $\mathrm{CAD}$ in two Asian populations. Clin Genet 50: $121-125$.

Sobel BE, Tarikuz Zaman AKM. 2011. Reperfusion injury: Double think or misnomer? Coron Artery Dis 22: 515517.

Sobel BE, Tarikuz Zaman AKM. 2012. Ignoratio elenchi: Myocardial conditioning and reperfusion "injury." Coron Artery Dis 23: 133-135.

Sütsch G, Kiowski W, Yan XW, Hunziker P, Christen S, Strobel W, Kim JH, Rickenbacher P, Bertel O. 1998. Shortterm oral endothelin-receptor antagonist therapy in conventionally treated patients with symptomatic severe chronic heart failure. Circulation 98: 2262-2268.

Teerlink JR. 2002. Recent heart failure trials of neurohormonal modulation (OVERTURE and ENABLE): Approaching the asymptote of efficacy? J Card Fail 8: $124-127$.

Thorin E, Clozel M. 2010. The cardiovascular physiology and pharmacology of endothelin-I. Adv Pharmacol 60: $1-26$.

Withering W. 1785. An account of the foxglove, and some of $i$ ts medical uses: With practical remarks on dropsy and other diseases. GGJ \& J. Robinson, London.

Zuckerman R, Milne CP. 2012. Industry perspective on personalised medicine. Nat Rev Drug Disc 11: 178. 


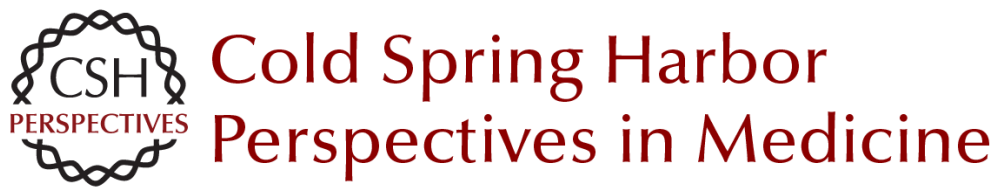

\title{
Cardiovascular Drug Discovery: A Perspective from a Research-Based Pharmaceutical Company
}

\author{
G. Gromo, J. Mann and J.D. Fitzgerald
}

Cold Spring Harb Perspect Med 2014; doi: 10.1101/cshperspect.a014092

\section{Subject Collection The Biology of Heart Disease}

The Genetic Basis of Aortic Aneurysm

Mark E. Lindsay and Harry C. Dietz

\section{Personalized Genomes and Cardiovascular Disease \\ Kiran Musunuru}

Complex Genetics and the Etiology of Human Congenital Heart Disease

Bruce D. Gelb and Wendy K. Chung

Genetic Networks Governing Heart Development Ashley J. Waardenberg, Mirana Ramialison, Romaric Bouveret, et al.

Heart Fields and Cardiac Morphogenesis Robert G. Kelly, Margaret E. Buckingham and Antoon F. Moorman

Regenerative Medicine: Transforming the Drug Discovery and Development Paradigm Sotirios K. Karathanasis

Myocardial Tissue Engineering: In Vitro Models Gordana Vunjak Novakovic, Thomas Eschenhagen and Christine Mummery

Pluripotent Stem Cell Models of Human Heart

Disease

Alessandra Moretti, Karl-Ludwig Laugwitz, Tatjana Dorn, et al.
Cardiac Cell Lineages that Form the Heart

Sigolène M. Meilhac, Fabienne Lescroart, Cédric Blanpain, et al.

Synthetic Chemically Modified mRNA (modRNA):

Toward a New Technology Platform for

Cardiovascular Biology and Medicine

Kenneth R. Chien, Lior Zangi and Kathy O. Lui

Next-Generation Models of Human Cardiogenesis via Genome Editing Xiaojun Lian, Jiejia Xu, Jinsong Li, et al.

How to Make a Heart Valve: From Embryonic Development to Bioengineering of Living Valve

Substitutes

Donal MacGrogan, Guillermo Luxán, Anita Driessen-Mol, et al.

Insights into the Genetic Structure of Congenital Heart Disease from Human and Murine Studies on Monogenic Disorders

Terence Prendiville, Patrick Y. Jay and William T. $\mathrm{Pu}$

Cardiovascular Drug Discovery: A Perspective from a Research-Based Pharmaceutical Company G. Gromo, J. Mann and J.D. Fitzgerald

Genetics and Disease of Ventricular Muscle Diane Fatkin, Christine E. Seidman and Jonathan G. Seidman

Embryonic Heart Progenitors and Cardiogenesis Thomas Brade, Luna S. Pane, Alessandra Moretti, et al.

For additional articles in this collection, see http://perspectivesinmedicine.cshlp.org/cgi/collection/ 